\title{
The effect of dihydroquercetin on the stability of consumer properties of chopped semi-finished meat
}

\author{
N. N. Shagaeva ${ }^{*}$, S. V. Kolobov ${ }^{2}$, and I. A. Zachesova ${ }^{1}$ \\ ${ }^{1}$ Moscow State Academy of Veterinary Medicine and Biotechnology - MBA named after K.I. \\ Scriabin, 23, ul. Akademika Skryabina, Moscow, 109472, Russia \\ ${ }^{2}$ Plekhanov Russian University of Economics, 36, Stremyanny per., Moscow, 117997, Russia
}

\begin{abstract}
The steadily increasing demand for semi-finished meat products is provided by the constantly expanding product range and improving its quality. In turn, quality stability is an important criterion for increasing sales. The article presents data on the effect of a natural antioxidant-dihydroquercetin on the stability of consumer properties of chopped semi-finished moose meat with the addition of beet fiber when stored at a negative temperature for 216 days. Dihydroquercetin was added in an amount of $0.05 \%$ by weight of the raw material. In the course of the work, generally accepted methods of studying organoleptic and microbiological quality indicators were used. The degree of oxidative deterioration of the product was checked by determining the acid, peroxide and thiobarbituric numbers. The conducted studies allowed us to conclude that the use of this food additive allows us to preserve the organoleptic and microbiological properties of the semi-finished product for a longer period by inhibiting the formation of oxidation products. The use of dihydroquercetin contributed to a decrease in the experimental sample of the semi-finished product on day 216 of the peroxide and acid number by 2 times, and the thiobarbituric number by 1.8 times in relation to the control. Thus, by reducing the oxidative damage of the semi-finished product, it is possible to influence its characteristics during storage.
\end{abstract}

\section{Introduction}

Every year, the modern consumer increasingly wants to buy food products of high organoleptic quality with improved functional and nutritional properties in combination with the traditional look and guaranteed safety for health. The demand for natural food products with minimal processing and without the use of artificial and synthetic food additives is increasing. At the same time, the consumer strives to buy products at reasonable prices and with an extended shelf life [1].

The shelf life of the product is determined by undesirable changes in quality caused by biological, chemical, biochemical reasons, or food safety concepts associated with the growth of food pathogens.

\footnotetext{
* Corresponding author : nata-shag@yandex.ru
} 
The rationale for a specific shelf life is based on safety, quality, and commercial solutions. For example, how does the shelf life of a product compare with the shelf life of similar products of competitors? Is this shelf life sufficient to sell a significant portion of the product before the expiration date, which minimizes the amount of inventory that needs to be disposed of after the expiration date? Is the shelf life long enough to allow you to purchase the product weekly? [2]

Currently, the food industry is working on the creation of new innovative meat products with a prolonged shelf life (storage). A new generation of products that should have antioxidant, anti-inflammatory, cholesterol-regulating, radioprotective and other useful properties [3]. Therefore, the food industry needs objective information about the shelf life of these products.

Refrigeration processing of meat products, as well as storage at appropriate low temperatures, is one of the most advanced and promising methods for extending their shelf life. When frozen, the most complete preservation of the original natural properties of meat products is achieved. However, even negative storage temperatures cannot stop the process of lipid oxidation. Oxidation products not only change the taste and smell of the product, but also lead to a deterioration in its quality and a shortened shelf life.

In an attempt to control the oxidation process, the food industry uses synthetic additives with antioxidant properties. However, with reports of the possible toxic effects of synthetic antioxidants and increasingly demanding consumer preferences for natural products and health benefits, there is increasing interest in alternative methods to slow the oxidation of lipids in food, such as the use of natural antioxidants.

Dihydroquercetin (DHA) is a natural bioflavonoid, a vitamin from the P group, isolated from the clump of Siberian, Gmelin or Daurian larch wood. In Russia, this substance is included in the list of permitted food additives and is recommended for use in the production of food products as an integral part of recipes.

Dihydroquercetin is non-toxic, physiologically harmless to the human body, characterized by stable antioxidant action, does not have allergenic, embryotoxic, immunotoxic, mutagenic properties. In addition to the antioxidant activity, DHA has a wide range of biological activity, has a capillary strengthening, anti-inflammatory, hepatoprotective, gastroprotective, hypolipidemic, radioprotective effect [4]

In connection with the above, the aim of the work is to study the effect of dihydroquercetin on the stability of consumer properties of chopped semi-finished meat.

\section{Materials and methods}

The material for the study was samples of semi-finished products - cutlets from moose meat. The cutlets were made using moose meat, pork, pork fat, fresh onion, chicken egg, black pepper, wheat bread, beet fiber, dihydroquercetin.

Beet fiber was added instead of part of wheat bread. Dihydroquercetin was added in an amount of $0.05 \%$ by weight of the raw material. Sample 1-control without dihydroquercetin, sample 2-with dihydroquercetin.

When developing the chopped semi-finished product, the classic technology and production modes of meat cutlets were taken as a basis. The developed samples of the chopped semi-finished product were stored for 216 days (reserve coefficient 1.2) at a temperature of minus $18^{\circ} \mathrm{C}$.

In the course of the study, organoleptic quality indicators, microbiological and lipid oxidation indicators were determined. Organoleptic evaluation of the quality of semifinished moose meat was carried out on a nine-point scale in accordance with GOST 99592015 " Meat and meat products. General conditions for organoleptic evaluation" after heat 
treatment (frying); Microbiological studies were carried out by seeding on nutrient media [5].

Fats are the most important components that determine the level of quality and shelf life of the product. To set the shelf life of minced meat semi-finished products, it is important to know the intensity of oxidation and hydrolysis of fats, for this purpose, the peroxide, acid and thiobarbituric lipid numbers of cutlets were determined.

\section{Results}

Regardless of the addition of dihydroquercetin, the cutlets should have a rounded-flattened shape, a homogeneous crushed mass without bones, cartilage, tendons, coarse connective tissue, blood clots and films. With the smell and color characteristic of the smell and color of the raw meat used in this semi-finished product. At the beginning of storage, all samples met these criteria.

On day 0 of storage, the presented samples of cutlets had an equally high overall score 8.7 points (Table 1 ).

Table 1. Organoleptic evaluation of cutlet samples.

\begin{tabular}{|c|c|c|c|c|}
\hline \multirow{2}{*}{$\begin{array}{l}\text { № } \\
\text { i/o }\end{array}$} & \multirow[t]{2}{*}{ Indicator name } & \multirow[t]{2}{*}{ Shelf life, day } & \multicolumn{2}{|c|}{ Assessment of cutlets, points } \\
\hline & & & control №1 & №2 \\
\hline 1. & appearance & $\begin{array}{c}0 \\
90 \\
180 \\
216\end{array}$ & $\begin{array}{l}8.7 \\
8.7 \\
7.8 \\
7.5\end{array}$ & $\begin{array}{l}8.7 \\
8.7 \\
8.4 \\
8.2\end{array}$ \\
\hline 2. & color on the cut & $\begin{array}{c}0 \\
90 \\
180 \\
216\end{array}$ & $\begin{array}{l}8.6 \\
8.6 \\
7.9 \\
7.6\end{array}$ & $\begin{array}{l}8.7 \\
8.7 \\
8.5 \\
8.3\end{array}$ \\
\hline 3. & smell & $\begin{array}{c}0 \\
90 \\
180 \\
216\end{array}$ & $\begin{array}{l}8.6 \\
8.6 \\
7.8 \\
7.6\end{array}$ & $\begin{array}{l}8.7 \\
8.7 \\
8.2 \\
8.0\end{array}$ \\
\hline 4. & taste & $\begin{array}{c}0 \\
90 \\
180 \\
216\end{array}$ & $\begin{array}{l}8.5 \\
8.4 \\
7.7 \\
7.5\end{array}$ & $\begin{array}{l}8.5 \\
8.5 \\
8.1 \\
7.9\end{array}$ \\
\hline 5. & consistency & $\begin{array}{c}0 \\
90 \\
180 \\
216\end{array}$ & $\begin{array}{l}9.0 \\
8.9 \\
8.4 \\
8.2\end{array}$ & $\begin{array}{l}9.0 \\
9.0 \\
8.9 \\
8.8\end{array}$ \\
\hline 6. & juiciness & $\begin{array}{c}0 \\
90 \\
180 \\
216\end{array}$ & $\begin{array}{l}8.6 \\
8.6 \\
7.9 \\
7.6\end{array}$ & $\begin{array}{l}8.6 \\
8.6 \\
8.5 \\
8.4\end{array}$ \\
\hline
\end{tabular}

At the end of the first 90 days, no signs of quality reduction were recorded in all samples, as well as any sharp differences between them. On day 180, the commission recorded differences in all quality indicators, the overall score decreased in the control sample by 1.1 times compared to the freshly prepared one, which may be due to oxidative processes occurring in the lipid fraction, as well as to the freezing of moisture during storage. On day 216, the overall assessment of the control sample decreased by 1 point, the 
tasters noted an increase in stiffness, which may be a manifestation of protein aggregation, a decrease in the color of the appearance, the appearance of a taste and smell of oxidized fat.

All of the above reasons for reducing the score of the control sample of cutlets can serve as reasons for reducing the shelf life of minced meat semi-finished products.

Sample No. 2 had a characteristic taste, smell, dense consistency and juiciness for 6 months of product storage. It had a high score (8.3 points) and even during backup storage, which is a manifestation of the antioxidant effect of dihydroquercetin.

During the study of samples for microbiological safety for 216 days (Fig. 1), the bacteria of the Escherichia coli group (BGCP, coliforms), pathogenic organisms, including bacteria of the genus Salmonella, Listeria monocytogenes, enteropathogenic escherichia (E. coli), Staphylococcus aureus (S. aureus) and mold fungi were not found.

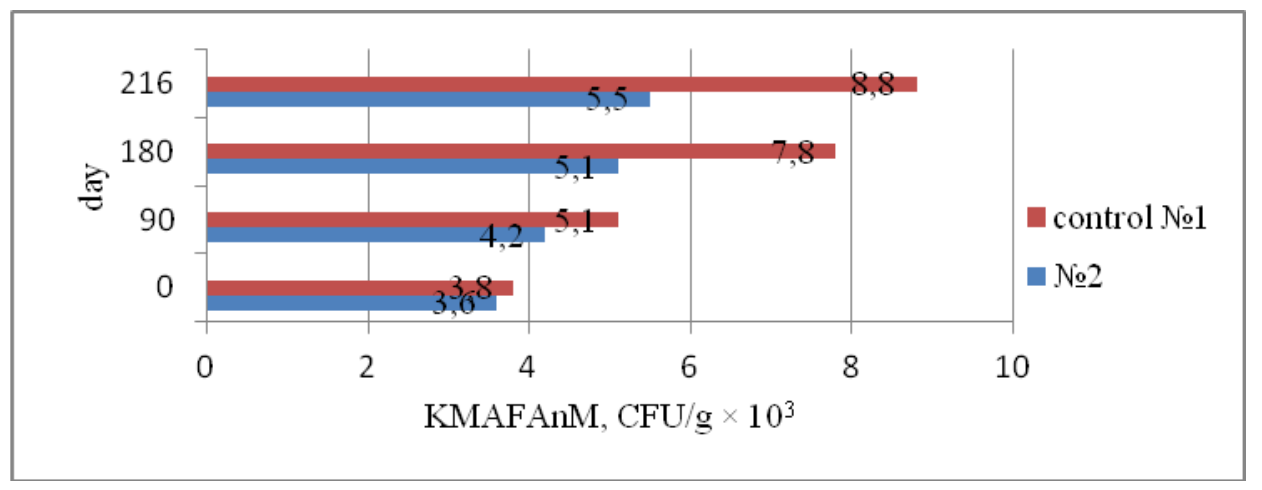

Fig. 1. Microbiological parameters of cutlet samples.

The increase in the total microbial number by 216 days for the control sample was 2.3 times, which is 1.6 times more than for the same period for sample No. 2. For cutlets with dihydroquercetin, this indicator was 1.5 times. The microbiological parameters for the samples under study did not exceed the permissible values and met the requirements of the regulatory and technical documentation for food products.

The depth and rate of changes in the composition and properties of lipids during hydrolysis and oxidation play a primary role in the formation of quality indicators of food products, so we determined the indicators of oxidative damage of lipids of samples. On day 216, the increase in the control sample was: peroxide number by 9.2 times, acid number by 3.7 times, and thiobarbituric number by 2.9 times in relation to day 0 . In the experimental sample, the increase by 216 days was: the peroxide number by 4.7 times, the acid number by 1.8 times, and the thiobarbituric number by 1.6 times in relation to 0 days. When comparing the samples of 216 days of storage with each other, it can be noted that in the experimental sample, the growth of the peroxide number was lower by $49.7 \%$, the acid number by $50.5 \%$ and the thiobarbituric number by $45.1 \%$ than in the control sample.

\section{Conclusion}

The results obtained allowed us to conclude that the prototype during storage was characterized by greater stability of consumer properties than the control, which confirms the antioxidant and bacteriostatic effect of dihydroquercetin, thereby extending the shelf life/storage of semi-finished meat products to six months. 


\section{References}

1. A.V. Ustinova Functional food products based on meat. All about meat. No. 3. P. 4-7 (2010)

2. G. Betts, L. Everis Shelf-life determination and challenge testing. Environmental Science (2000)

3. G. V. Chebakova, M. A. Aslanova, A.V. Ovakimyan. A functional product for improving the quality of life of the elderly. Commodity science, technology and expertise: Innovative solutions and development prospects: Materials of the National scientific and practical conference, Moscow 14-15 June 2018-Moscow: ZooVetKniga. pp. 80-84. (2018).

4. N. N. Shagaeva, S. V. Kolobov. The effect of dihydroquercetin on the functionaltechnological and structural-mechanical properties of chopped semi-finished products from moose meat. "Commodity science, technology and expertise: innovative solutions and development prospects": Mat. of the national scientific and practical conference "Commodity Science, Technology and Expertise: innovative solutions and Development Prospects" - October 28, 2020 Moscow: Publishing House "ZooVetKniga", pp. 158-165. (2020).

5. I.A. Zachesova, S.V. Kolobov, N.N. Shagaeva The effect of beet fibers on the properties of elk meat semi-finished products. E3S Web Conf. Ecological and Biological WellBeing of Flora and Fauna (EBWFF-2020). Volume 203. P. 10. (2020). 